\title{
IMUNOFLUORESCÊNCIA INDIRETA NO PÊNFIGO FOLIÁCEO ENDÊMICO. CONTRIBUIÇĀO PARA SUA PADRONIZAÇÃO
}

\author{
Horacio FRIEDMAN (1), Iphis T. CAMPBELL (1), Rosicler ROCHA ALVAREZ (1), Luis A. DIAZ (2), \\ Raymundo MARTINS DE CASTRO (3), Isaac ROITMAN (4), Rosa M. PARREIRAS (1) \& Alberto N. RAICK (1).
}

\begin{abstract}
RESUMO
O propósito da presente investigação foi padronizar a reação de imunofluorescência indireta para Pênfigo Foliáceo Endêmico (Fogo Selvagem). Verificamos que a pele humana normal é o substrato ideal e que pode proceder de prepúcio, cabeça, pescoço ou da parede abdominal anterior. A lavagem prévia da pele precedendo a incubação com o soro deve ser evitada pois a antigenicidade pode ser diminuída. O TAS-cálcio preserva as propriedades antigênicas da pele e deve ser preferido como diluente para os soros. Lâminas cobertas com albumina são úteis porque aumentam a aderência dos cortes de pele. A diluiçāo apropriada do conjugado é convenien temente determinada pelo teste de imunodifusão radial (método de Ouchterlony). Com referência à correlação entre título de anticorpos e atividade clínica, concluímos que um título igual ou maior do que 160 era de mau prognóstico pois estava associado à forma generalizada da doença ou à casos de forma localizada refratários à terapêutica usual. Contudo, esta obervação requer confirmação através de estudos que envolvam uma abordagem clínica apropriada.
\end{abstract}

UNITERMOS: Pênfigo foliáceo endêmico; Imunofluorescência indireta.

\section{INTRODUÇÃO}

Fogo Selvagem, mais apropriadamente denominado Pênfigo Foliáceo Endèmico (PFE), é forma de pênfigo foliáceo que ocorre com alta incidência e freqüente distribuiçāo familiar na América Latina, particularmente no Brasil ${ }^{2.3 .6 .}$ 12. 16, 17. 27. 31 estimando-se atualmente em mais de 15.000 o número de $\operatorname{casos}^{16}$.

A patogênese do PFE decorreria da açāo de um auto-anticorpo cujo alvo é a substância inter- celular da epiderme ${ }^{7}$. Este anticorpo pertence geralmente à classe IgG e pode ser demonstrado por imunofluorescência direta das lesōes cutâneas $^{9,24}$ ou por imunofluorescência indireta no soro dos pacientes ${ }^{9}{ }^{10}$. Como o auto-anticorpo não é espécie-específico, pode-se utilizar epitélio escamoso de pele ou de mucosa de várias espé cies animais para a realizaçāo da reaçāo de imunofluorescência indireta, o que permitiu a padro-

(1) Laboratório de Patologia e Serviço de Dermatologia da Fundaçāo Universidade de Brasília. Brasília, DF, Brasil.

(2) Immunodermatology Unit, Department of Dermatology. Johns Hopkins Medical Institutions. Baltimore, MD, USA

(3) Departamento de Dermatologia, Escola Paulista de Medicina. São Paulo, SP, Brasil.

(4) Laboratório de Microbiologia e Imunologia da Fundação Universidade de Brasília. Brasília, DF, Brasil

Endereço para correspondência: Dr. Horácio Friedman, Laboratório de Patologia da Faculdade de Ciências da Saúde. Univer sidade de Brasília. CEP 70910. Brasilia, DF, Brasil. 
FRIEDMAN, H.; CAMPBELL, I. T.: ALVAREZ, R. R.; DIAZ, L. A.; CASTRO, R. M. de; ROITMAN, I.; PARREIRAS, R. M. \& RAICK, A. N. - Imunofluorescência indireta no pênfigo foliáceo endémico. Contribuição para sua padronizaçảo. Rev. Inst. Med. trop. S. Paulo, 31(3): 158-168, 1989.

nizaçāo de métodos semi-quantitativos de titulaçào de anticorpos ${ }^{10}$.

A reação de imunofluorescência indireta pa ra pênfigo é o único parâmetro laboratorial espe cífico e semi-quantitativo de que dispomos, re presentando ao lado da avaliaçăo clinica um da do importante para a quantificaçāo aproximada da gravidade da doença. Em casos incaracte rísticos, ela tem valor diagnóstico, como exame complementar. Vários autores postulam ainda seu valor prognóstico e de orientador terapêutico, permitindo que se regule a dose de medicamento de acordo com o nivel sérico de anticor$\operatorname{pos}^{8 .}{ }^{23}$. Finalmente, a reação pode ser utilizada para inquéritos soro epidemiológicos ${ }^{25}$, aspecto ainda carente de abordagem em nosso país, principalmente se considerarmos que os pacientes que procuram o hospital provavelmente correspondem apenas à porção visivel do "iceberg" representativo da população atingida pela doença.

A falta de padronizaçāo universal da reação e as controvérsias que cercam a correlação entre títulos de anticorpos e gravidade da doença ( Ta- bela 1) motivaram a presente investigaçāo na qual procuramos comparar vários substratos, analisar as variáveis influentes sobre a reaçāo, testar a reprodutibilidade desta e avaliar a correlaçāo clínico-sorológica.

\section{MATERIAL E MÉTODOS}

\section{A. Procedimentos gerais}

\section{Pacientes e soros}

Estudamos pacientes atendidos na Unidade de Dermatologia do Hospital Docente Assistencial de Brasilia. O diagnóstico de PFE foi baseado em dados clínicos, exame histopatológico das lesões e imunofluorescência direta das mesmas. A classificaçāo clínica utilizada foi a proposta pelo "grupo cooperativo de pênfigo"16. Esta classificaçāo aceita duas formas ativas da doença - a localizada e a generalizada. As reaçoes de imunofluorescência direta e os exames histopatológicos foram realizados no Laboratório de $\mathrm{Pa}$ tologia da Fundação Universidade de Brasília (UnB). As reaçōes de imunofluorescência indi.

TABELA 1

Tipos de substratos utilizados em diferentes laboratórios e respectivos estudos sobre a correlaçâo clínico-sorológica.

\begin{tabular}{|c|c|c|}
\hline GRUPO & SUBSTRATO & CORRELAÇĀO \\
\hline ANHALT et alii, 1982 & língua de rato & não estudada \\
\hline BEUTNER et alii, 1980 & esôfago de macaco & positiva \\
\hline CRESWELL et alii, 1981 & pele humana & inconstante \\
\hline FEIBELMAN et alii, 1981 & esôfago de macaco & positiva \\
\hline FITZPATRICK \& NEWCOMER, 1980 & esôfago de macaco & inconstante \\
\hline KATZ et alii, 1969 & pele humana & positiva \\
\hline GOLAN et alii, 1984 & lábio de cobaia & inconstante \\
\hline JUDD \& LEVER, 1979 & esôfago de cobaia & ausente \\
\hline JUDD \& MESCON, 1979 & vários & inconstante \\
\hline MATIS et alii, no prelo & pele humana & não estudada \\
\hline RIVITTI, 1972 & esôfago de cobaia & inconstante \\
\hline TAKAHASHI, 1981 & esôfago de cobaia & inconstante \\
\hline WEISSMAN et alii, 1978 & pele humana & positiva \\
\hline
\end{tabular}

Correlação: correlação entre atividade clínica e títulos de anticorpos no soro.

Não estudada: não houve estudo sobre a correlação.

Inconstante: houve correlaçāo positiva em alguns casos apenas.

Positiva: houve correlaçāo positiva na maioria ou na totalidade dos casos.

Ausente: não houve correlação. 
FRIEDMAN, H.; CAMPBELL, I. T.; ALVAREZ, R. R.; DIAZ. L. A.; CASTRO, R. M. de; ROITMAN, I.: PARREIRAS. R. M. \& RAICK, A. N. - Imunofluorescencia indireta no penfigo foliáceo endémico. Contribuiçāo para sua padroniza ça. Rev. Inst. Med. trop. S. Paulo, 31(3): 158.168, 1989.

reta foram realizadas na UnB e na Immunodermatology Unit da Johns Hopkins University (IDU). A investigação compreendeu très fases - uma preliminar na UnB, uma intermediária na IDU e uma final na UnB. Na UnB, foram titulados 41 soros, sendo 22 de pacientes com doença localizada, dez de pacientes com doença generalizada, um de paciente em fase inativa e oito de parentes de doentes, isto é, de pessoas normais provenientes de áreas endêmicas. Na IDU, titulamos 92 soros, sendo 50 de doentes com forma localizada, 19 de forma generalizada, nove de doentes em fase inativa e 14 soros de pessoas normais de áreas endêmicas. Dos 41 soros testa. dos na UnB, 23 foram também testados na IDU. permitindo as comparaçōes demonstradas nas tabelas 7 e 8 .

\section{Tampóes}

Utilizamos a soluçāo salina com tampảo fos fato (PBS), em pH 7,2 e o TRIS-acetato cálcio (TAS cálcio) em pH 7,5, cuja soluçāo-estoque $10 \mathrm{x}$ é preparada com $48,40 \mathrm{~g}$ de Trisma base $(0,01$ $\mathrm{M})$ dissolvidas em 3 litros de água destilada. Adi ciona-se $340 \mathrm{~g}$ de $\mathrm{NaCl}(0,85 \%)$ e titula-se a $\mathrm{pH}$ 7,5 com ácido acético. Adiciona-se $22,2 \mathrm{~g}$ de cloreto de cálcio e $8 \mathrm{~g}$ de azida de sódio. Completa-se o volume a 4 litros, empregando-se diluiçōes a 1:10 com água destilada no momento de usar ${ }^{4}$.

\section{Conjugados}

Empregamos conjugados obtidos comer cialmente da Biolab (na fase preliminar) e da Cappel (na IDU e na fase final). Na fase preliminar, determinamos a diluiçāo de uso através de reaçoes de imunofluorescencia direta empregando cortes em criostato de baço humano obtido em necrópsias. Na IDU, a diluição de uso era determinada por imunodifusāo radial _-. método de Ouchterlony - (Fig. 1) que passamos a adotar no Brasil ${ }^{4}$.

\section{Substratos}

Na fase preliminar, amostras de pele humaha obtida por cirurgia plástica de mama, língua de rato, lábio de camundongo, esófago de cobaia e pele de camundongo recém-nascido eram congeladas e armazenadas em nitrogênio liquido.

Na IDU, onde utilizamos prepúcio de recém nascidos obtido por circuncisāo e na UnB. na

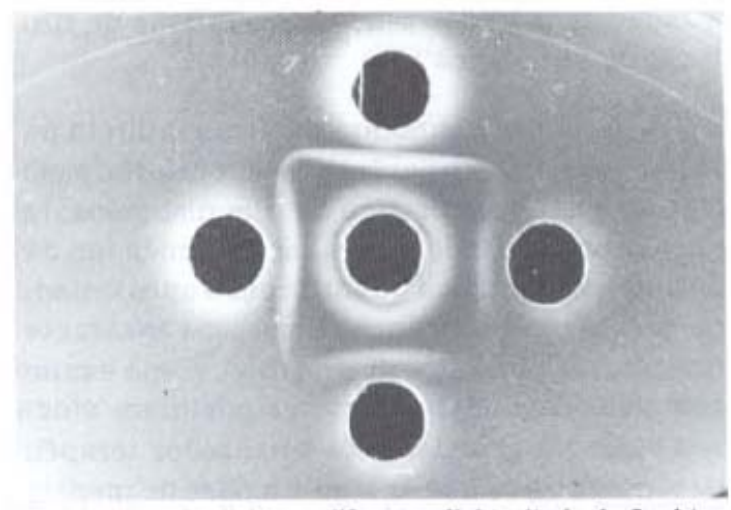

Fig. 1 - Reaçáo de imunodifusâo radial (método de Ouchterlony) empregada para definir a diluiçáo ideal de uso do conju gado anti-IgG, O orificio superior, envolto pelo halo mais briIhante, continha conjugado puro, nào diluido. 0 orificio đa esquerda continha conjugado diluido a 1:2. No orificio inferior, havia conjugado diluido a 1:4 e no da direita, a 1:8. No orificio central, colocou-se soro humano normal. Diante da presença de linha de precipitaçáo relativamente fraca mas bem evidente em correspondència à diluiçáo 1:8, este conjugado fol empre gado na dlluị̧âo 1:16.

fase final, quando empregamos pele humana de regiāo abdominal obtida por cirurgia de corre çào de hérnia, as amostras eram colocadas na resina denominada composto OCT, da Miles Laboratories, Inc., orientadas e imersas em nitrogênio líquido, formando-se blocos sólidos que eram armazenados em congelador a $-20^{\circ} \mathrm{C} . \mathrm{Em}$ experimentos destinados à comparaçāo de substratos, montávamos num mesmo bloco de OCT os vários espécimes a serem testados.

\section{Preparo das lâminas}

Na fase preliminar, as lāminas eram simples mente desengorduradas com banhos de éter e acetona, sendo usadas logo após a secagem. Na IDU e na fase final, empregamos lâminas tratadas com albumina ${ }^{45}$.

\section{Cortes em criostato}

Os blocos foram cortados em criostato Leitz na UnB e em criostato da American Optical na IDU. Três cortes de $5 \boldsymbol{\mu} \mathrm{m}$ cada eram colocados em cada lámina.

\section{Incubação e lavagem dos cortes}

A incubação dos cortes com os soros e com o conjugado foi feita à temperatura ambiente. 
FRIEDMAN, H.; CAMPBELL, I. T: ALVAREZ, R. R.: DIAZ, L. A.; CASTRO, R. M. de; ROITMAN, I. PARREIRAS, R. M. \& RAICK, A. N. - Imunofluorescéncia indireta no pénfigo foliaceo endèmico. Contribuiçäo para sua padronizá f̧ào. Rev. Inst. Med. trop. S. Paulo, 31(3): 158168,1989

em câmara úmida, por 30 minutos. Após as incu bações, os cortes eram subrnetidos a duas lavagens de 10 minutos cada, também à temperatura ambiente, com PBS ou TAS-cálcio.

\section{Montagem das lâminas}

$\mathrm{Na}$ fase preliminar, montávamos as lâminas com glicerina tamponada, pH 7,2. Na IDU e na fase final, usamos o Permafluor da Lipshaw ${ }^{4}$.

\section{Leitura, análise e documentaçāo das rea- ções}

Procedeu-se o exame das reações de imunofluorescência em microscópios Zeiss, modelo de trans-iluminação (UnB) e da Olympus, modelo de epi-iluminaçāo (IDU). Para as fotografias, em pregou-se filmes Kodacolor e TRIS $\mathrm{X}$, ambos de 400 ASA, com exposiçảo média de 2 a 3 minutos. À intensidade da reação, foram conferidos os va lores:

0 : reação negativa:

$1+$ : reaçâo positiva mas de fraca intensidade, pouco evidente;

$2+$ : reação positiva de moderada intensidade, bem evidente;

$3+$ : reação positiva de forte intensidade.

Foi considerada significativa diferença de duas ou mais diluiçōes no resultado da titulaçāo.

\section{Esquemas gerais das reaçôes}

No decorrer do trabalho e com o evolver do método, empregamos os esquemas de reaçáo descritos a seguir.

Esquema I (empregado no início da fase preliminar na UnB)

cortes (vários substratos) $\longrightarrow$ acetona $\longrightarrow$ PBS

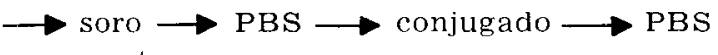

$\rightarrow$ montagem.

Esquema II (empregado no fim da fase preliminar na UnB)

cortes (língua de rato $\longrightarrow$ soro $\longrightarrow$ PBS $\rightarrow$ conjugado $\longrightarrow$ PBS $\longrightarrow$ montagem

\section{Esquema III (empregado na IDII)}

cortes (pele humana de prepúcio de recem nas cido $\rightarrow$ soro diluído em TAS cálcio $\rightarrow$ TAS calcio $\rightarrow$ conjugado $\rightarrow$ TAS - calcio $\rightarrow$ mon tagem.

\section{Esquema IV (empregado na fase finalt}

cortes (pele humana de abdómen) $\longrightarrow$ soro diluído em TAS-cálcio $\longrightarrow$ TAS cálcio $\rightarrow$ con jugado $\rightarrow \mathrm{PBS} \rightarrow$ montagem.

Um soro positivo de paciente com PFE e um soro negativo de pessoa normal serviram de controles.

\section{B. Procedimentos Específicos}

Estes experimentos estudaram a influéncia de algumas variáveis sobre as reaçoes. Assim. comparamos vários substratos e analisamos os efeitos da acetona, do composto OCT, da lava gem prévia com PBS, do congelamento rápido ou lento dos substratos e do armazenamento das láminas. Para o composto OCT, titulamos 4 so ros empregando substratos (língua de rato e eso fago de cobaia) embebidos ou nào no mencio nado composto. Na avaliaçào do efeito da veloci dade de congelamento, titulamos 7 soros utili zando linqua de rato congelada rapidamente com nitrogénio líquido ou lentamente dentro do criostato. O efeito do armazenamento das lámi nas com cortes foi analisado ao se titular 4 soros empregando cortes preparados no mesmo dia versus cortes preparados 7 dias antes.

\section{RESULTADOS}

Ao compararmos os varios substratos, leva mos em consideraçào os títulos obtidos, a clare za da reação, a facilidade para a obtenção do espécime e a qualidade dos cortes em criostato. Diante deste conjunto de dados, a lingua de rato despontou como um substrato satisfatório em nossos experimentos preliminares (Tabelas 2, 3 e 4). Na IDU e na fase final, a pele humana foi considerada o substrato ideal.

Com o emprego da acetona (comparar 'labe las 3 e 4 ) e da lavagem prévia com PBS (Tabelas 5 e 6 ), as reações apresentaram pior qualidade e títulos mais baixos. 
FRIEDMAN, H.; CAMPBELl, I. T.; ALVAREZ, R. R.; DIAZ, L. A.: CASTRO, R. M. de: ROITMAN, I; PARREIRAS, R. M. \& RAICK. A. N. - Imunofluorescència indireta no pènfigo foliáceo endêmico. Contribuiçào para sua padroniza. cào. Rev. Inst. Med. trop. S. Paulo. 31(3): 158 168, 1989.

TABELA 2

Comparaçào entre diferentes substratos

\begin{tabular}{lrrrr}
\hline & \multicolumn{4}{c}{ TíTULOS } \\
Soro N & Li & La & Ec & Ph \\
\hline 221 & 40 & 40 & 40 & 0 \\
220 & 0 & 0 & 0 & 0 \\
219 & 40 & 80 & 40 & 0 \\
218 & 80 & 40 & 0 & 1.280 \\
217 & 320 & 320 & 320 & 160 \\
212 & 640 & 320 & 80 & 320 \\
139 & 0 & 80 & 0 & 0 \\
127 & 320 & 320 & 0 & 320 \\
\hline
\end{tabular}

Foi empregado o esquema I de reaçāo (descrito no item IV.A). Li: língua de rato.

Lá: lábio de camundongo.

Ec: esôfago de cobaia.

Ph: pele humana.

TABELA 3

Comparaçāo entre diferentes substratos

\begin{tabular}{crrrrr}
\hline & \multicolumn{5}{c}{ TiTitos } \\
Soro N: & Li & La & Ec & Pr & Pc \\
\hline 224 & 160 & 20 & 0 & 20 & 20 \\
223 & 0 & 0 & 0 & 0 & 0 \\
171 & 20 & 20 & 0 & 0 & 0 \\
129 & 80 & 80 & 0 & 80 & 80 \\
92 & 160 & 320 & 80 & 1.280 & 160 \\
75 & 160 & 160 & 160 & 160 & 80 \\
\hline
\end{tabular}

Foi empregado o esquema I de reação (descrito no ítem IV.A). Li: lingua de rato.

La: lábio de camundongo.

Ec: esofago de cobaia

Pr: pele de rato.

Pc: pele de camundongo.

TABELA 4

Comparaçāo entre diferentes substratos

\begin{tabular}{crrrrr}
\hline & \multicolumn{5}{c}{ TíTLLO } \\
Soro N: & Li & La & Ec & Pr & Pc \\
\hline 224 & 320 & 160 & 320 & 320 & 160 \\
223 & 160 & 80 & 160 & 320 & 40 \\
198 & 160 & 40 & 20 & 40 & $n / \mathrm{e}$ \\
193 & 80 & 40 & 0 & 20 & $\mathrm{n} / \mathrm{e}$ \\
172 & 20 & 40 & 20 & 40 & $\mathrm{n} / \mathrm{e}$ \\
171 & 0 & 20 & 0 & 0 & 20 \\
129 & 640 & 320 & 160 & 320 & 320 \\
109 & 40 & 80 & 0 & 80 & $\mathrm{n} \cdot \mathrm{e}$ \\
92 & 1.280 & 1.280 & 1.280 & 1.280 & 1.280 \\
75 & 80 & 40 & 0 & 80 & 40 \\
64 & 0 & 0 & 0 & 0 & 0 \\
61 & 80 & 20 & 20 & 80 & 20
\end{tabular}

Nestas reaçóes, foi abolida a fixaça com acetona

Li: lingua de rato

La: lábio de camundongo.

Ec: esôfago de cobaia.

Pr: pele de rato.

PC: pele de camundongo.

ne: nao examinado.
TABELA 5

Efeito da lavagem previa com PBS

\begin{tabular}{crcc}
\hline & \multicolumn{3}{c}{ INTENSIDADE DA REAÇ் } \\
Soro $N:$ & S/PBS & PBS-9 min & PBS-30 min \\
\hline & $3+$ & $2+$ & $1+$ \\
241 & $3+$ & $1+$ & $2+$ \\
238 & $23+$ & $2+$ & $1+$ \\
236 & $3+$ & $2+$ & 0 \\
235 & $3+$ & $1+$ & $1+$ \\
234 & $3+$ & $2+$ & $1+$ \\
233 & $3+$ & $2+$ & $1+$ \\
232 & $23+$ & $2+$ & 0 \\
231 & $23+$ & $2+$ & $1+$ \\
229 & $3+$ & & \\
\hline
\end{tabular}

* Avaliou-se a intensidade da reaçāo numa única diluiçảo de soro (1:20).

S PBS: a lavagem prévia com PBS foi abolida.

PBS-9 min: os cortes foram submetidos a 3 lavagens prévias de 3 minutos cada, precedendo a incubaçāo com os soros.

PBS-30 min: os cortes foram submetidos a 3 lavagens prévias de 10 minutos cada, precedendo a incubaçáo com os soros.

0 : reaçāo negativa.

$1+$ reaçáo positiva de fraca intensidade, pouco evidente.

$2+$ : reaça positiva de moderada intensidade, bem evidente.

$3+$ : reaça positiva de for te intensidade.

TABELA 6

Efeito da lavagem previa com PBS.

\begin{tabular}{lrr}
\hline & \multicolumn{2}{c}{ TITULOS } \\
Soro N: & S:PBS & c/PBS \\
\hline 257 & 320 & 80 \\
252 & 80 & 40 \\
250 & 40 & 0 \\
248 & 640 & 160 \\
241 & 2.560 & 40 \\
238 & 2.560 & 5.120 \\
236 & 160 & 0 \\
234 & 0 & 0 \\
233 & 320 & 20 \\
231 & 1.280 & 0 \\
\hline
\end{tabular}

SPBS: a lavagem previa com PBS foi abolida.

c.PBS: os cortes foram submetidos a 3 lavagens com PBS de 10 minutos cada, antes da ineubaçāo com os soros.

Nảo houve variaçāo na qualidade ou no títu lo das reaçōes em decorrência da utilizaçāo do composto OCT, do congelamento lento ou do armazenamento das lâminas.

As reaçōes realizadas na IDU se caracterizaram por excelente contraste imunológico, tornando a leitura fácil e indubitável (Figura 2). Os resultados estāo resumidos nas figuras 3 a 7 , mostrando que 13 das 14 pessoas normais $(91,85 \%)$ e oito dos nove pacientes em fase inativa $(88,88 \%)$ apresentaram reação negativa. Os 
FRIEDMAN, H; CAMPBELL, I. T; ALVAREZ, R. R; DIAZ, L. A ; CASTRO, R. M. de; ROITMAN, I; PARREIRAS, R. M. \& RAICK, A. N. - Imunofluorescencia indireta no penfigo foliaceo endémico Contribuiçào para sua padroniza çāo. Rev. Inst. Med. trop. S. Paulo, 31(3): 158-168, 1989

50 soros de doentes com forma localizada exibiram títulos variando de 40 a 1280 . Os dois casos com título 40 e 14 dos 16 casos com título 80 mostraram poucas lesões (menos de 10 ) e neces sitaram de doses diárias de manutenção meno res do que $20 \mathrm{mg}$ de prednisona. Quatro dos sete pacientes com título 160 recebiam $60 \mathrm{mg}$ de pred nisona por dia na data da colheita do soro. Outro paciente desenvolveu forma generalizada em dois meses. Os 13 pacientes com forma localizada e título 320 exibiam 20 ou mais lesōes e atividade maior das lesōes reritema acentuado, exsudato etc.). Dois deles evoluíram para forma generalizadia. Em seis, houve tendência a recidi vas e o controle terapêutico foi difícil mesmo com doses diárias de 20 a $40 \mathrm{mg}$ de prednisona. Esta mesma resistência ao tratamento caracterizou os pacientes com forma localizada e título 640 , dois dos quais desenvolveram forma genera lizada. A doente com título 1.280 classificada cli nicamente como portadora de forma localizada apresentava sindrome de Cushing iatrogênica mantida que estava sob a dose de $40 \mathrm{mg}$ de prednisona por dia. Entre várias recidivas, esta pa. ciente chegou a desenvolver forma generalizada. Dentre os 19 casos com forma generalizada, dois $(10,5 \%)$ apresentaram título 160 , sete $(36,8 \%)$ mostraram titulo 320 , dois casos $(10,5 \%)$ exibiram título 1.280 , um caso $(5,3 \%)$ teve título 2.560 e dois casos $(10,5 \%)$ apresentaram título 5.120. Títulos entre 160 e 1.280 corresponderam a formas generalizadas de aspecto variável, tanto no que tange à extensão da área envolvida, como em relação à intensidade de atividade das lesōes e ao tipo destas, isto é, se bolhosas, erodidas, exfoliativas etc. Os quadros generalizados com acometimento de mais de $90 \%$ da superfície cor. pórea mostraram títulos maiores ou iguais a 1.280. Nos dois casos com título 5.120, o acometimento foi total e do tipo eritrodérmico.

As reaçôes realizadas na fase final na $U n B$ apresentaram qualidade e títulos comparáveis aos da IDU (Tabela 8). O esôfago de cobaia nāo forneceu nunca resultados superiores à pele hu mana. Propiciou, porém, valores significativamente inferiores (duas ou mais diluiçöes de diferença) em cinco dos casos testados (Tabela 8 ).

\section{DISCUSSÃo}

Um dos mais controversos aspectos relacionados à reaçāo de imunofluorescência indireta
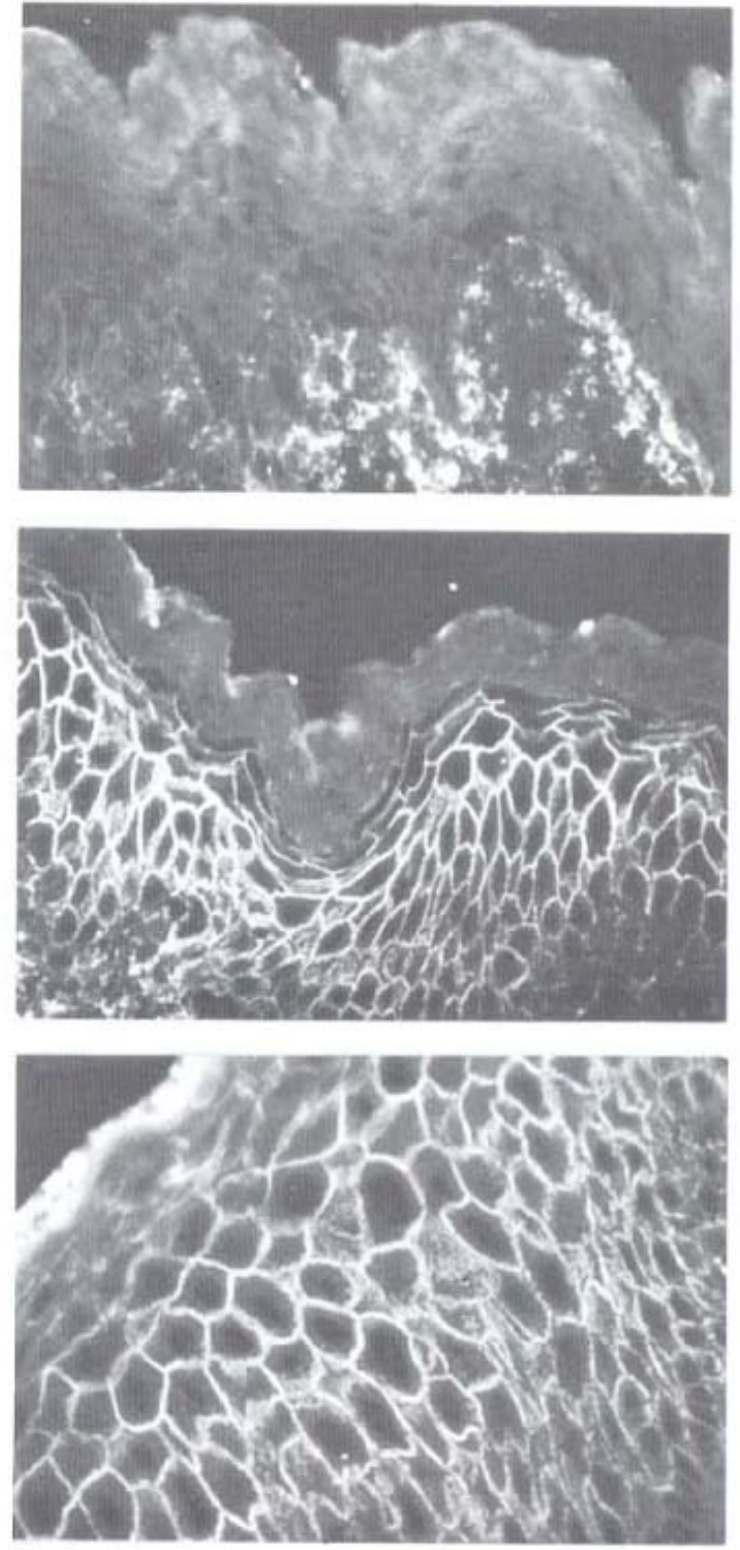

Fig. 2 - Reaçóes de imunofuorescéncia indireta empregando pele humana normal como substrato e os procedimentos men cionados no texto. A figura 2 a corresponde a uma reaçáo nega. tiva, controle, em que se utilizou soro de pessoa normal. As figuras $2 b$ e $2 c$ sao de reaçoes positivas, obtidas com soros de doentes de PFE, nas quais é nitida a distribuiçáo inter-ce. lular da IgO x 320 (figuras $2 \mathrm{a}$ e 2b; x 400 (figura 2c).

para pênfigo é a escolha do substrato ideal, tema discutido por vários autores ${ }^{1}$. 8. 13.18 .21 .22 .25 .31 . O esófago de macaco é recomendado por vários autores ${ }^{8,18}$. Não obstante, segundo SABOLINS KI et al. ${ }^{30}$, o esôfago de cobaia fornece títulos mais elevados do que o esôfago de macaco em 
FRIEDMAN, H.; CAMPBELL, I. T.; ALVAREZ, R. R.; DIAZ, L. A.; CASTRO, R. M. de; ROITMAN, I.; PARREIRAS, R. M. \& RAICK, A. N. - Imunofluorescência indireta no pênfigo foliáceo endêmico. Contribuiçāo para sua padronizaçäo. Rev. Inst. Med. trop. S. Paulo, 31(3): 158-168, 1989.

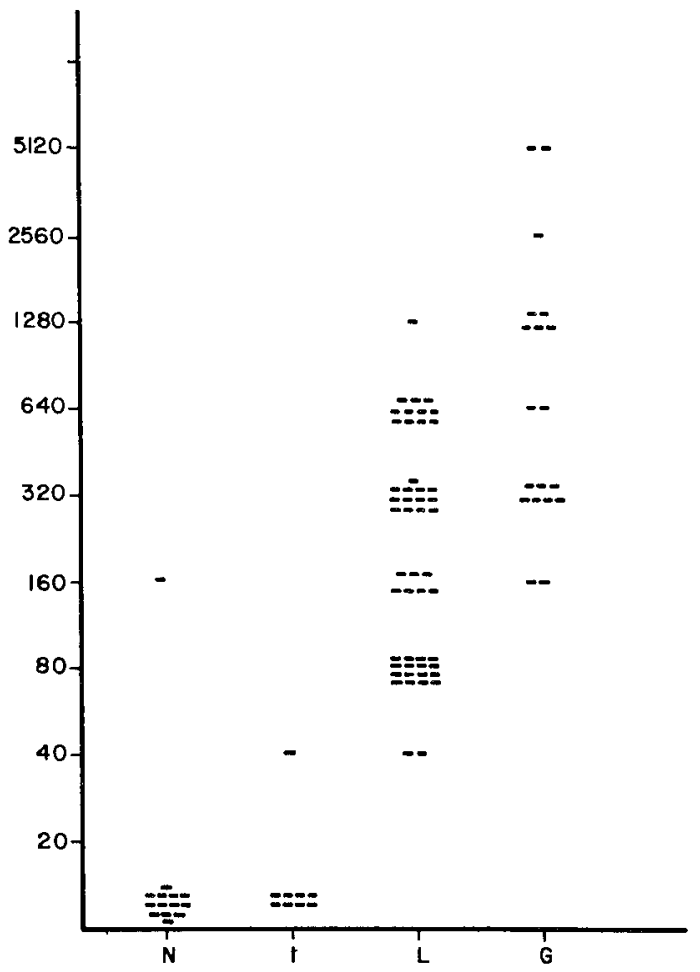

Fig. 3 - Distribuição de títulos de anticorpos por atividade clínica de PFE. N: pessoas normais, sadias; I: pacientes de PFE em inatividade clínica; $L$ : pacientes com a forma localizada de $P F E ; G$ : pacientes com a forma generalizada de $\mathrm{PFE}$.

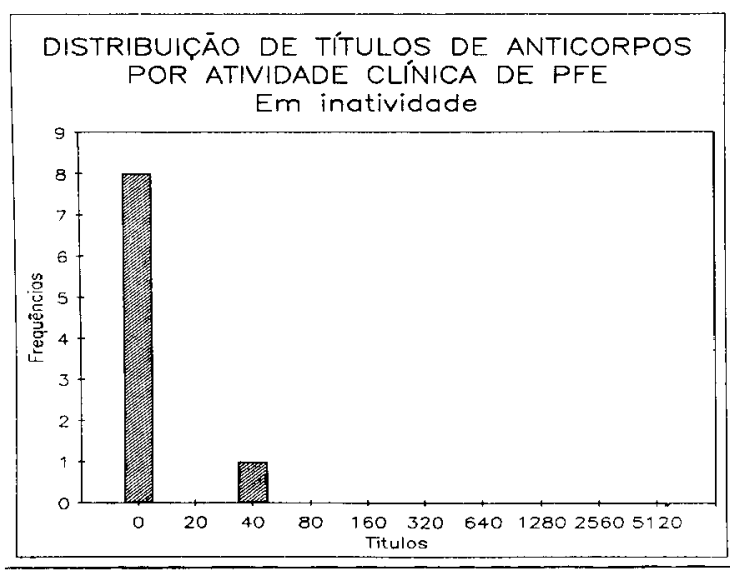

Fig. 4 - Histograma representativo da distribuição dos títulos de anticorpos em soros de pessoas sadias.

casos de PFE, o inverso sucedendo no pênfigo vulgar. Assim, no Brasil, o esôfago de macaco nāo seria o substrato ideal. Outros trabalhos recentes mencionam inferioridade do esôfago de macaco em relação à pele humana tanto em ca-

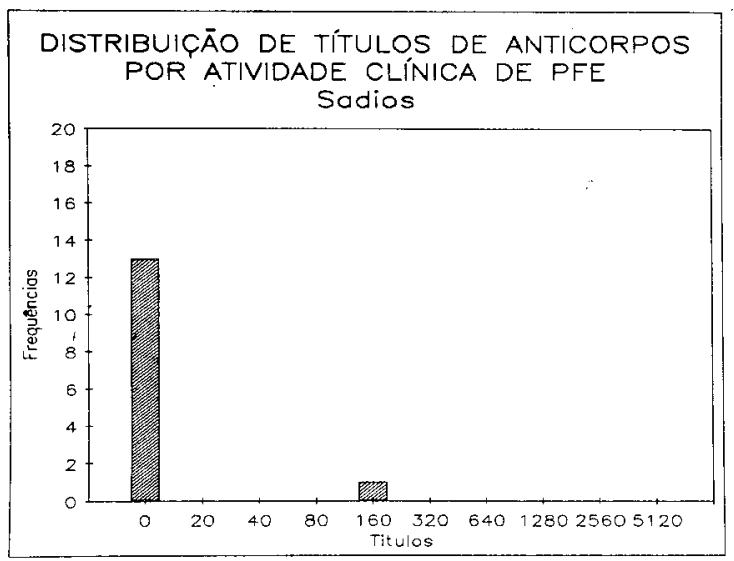

Fig. 5 - Histograma representativo da distribuição dos títulos de anticorpos em soros de pacientes em inatividade clínica.

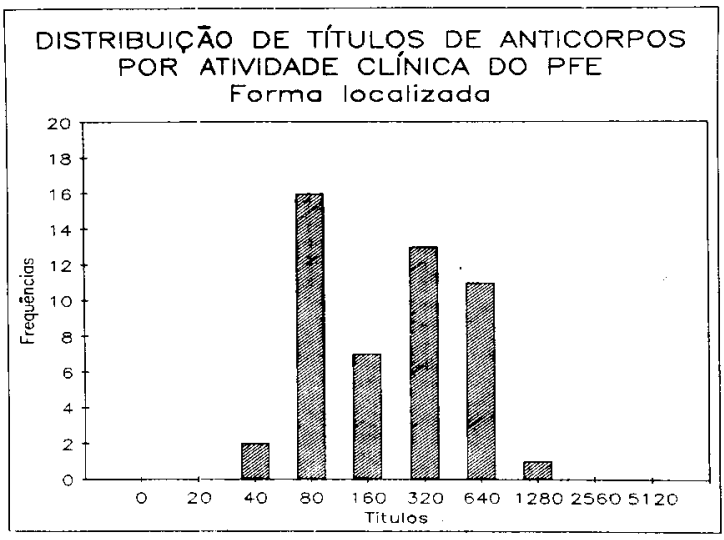

Fig. 6 - Histograma representativo da distribuição dos títulos de an íicorpos em soros de pacientes com forma localizada de PFE.

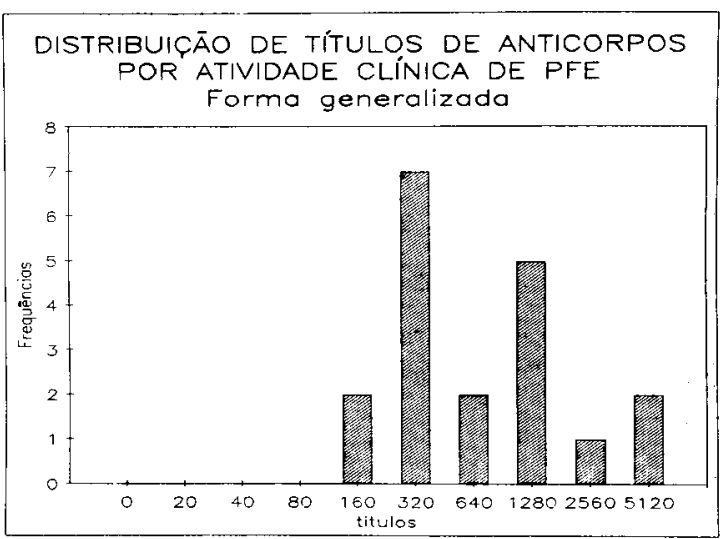

Fig. 7 - Histograma representativo da distribuição dos títulos de anticorpos em soros de pacientes com forma generalizada de PFE 


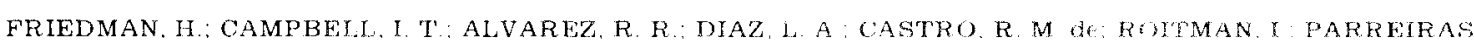

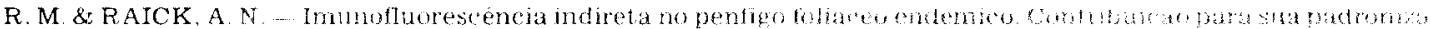
çào. Rev. Inst. Má trop. S. Paulo, 31 (3): 158 168, 1989

TABELA?

Comparacao entre titulos obtidos na UnB, hio final dat tase proliminar ena Ii)

\begin{tabular}{lrr}
\hline & & \\
\hline & UnH & TTULOS \\
\hline 254 & 20 & 40 \\
250 & 160 & 320 \\
248 & 2560 & 1.280 \\
245 & 0 & 0 \\
244 & 1280 & 640 \\
243 & 160 & 80 \\
241 & 2560 & 5120 \\
239 & 0 & 0 \\
238 & 160 & 640 \\
236 & 160 & 160 \\
233 & 160 & 640 \\
232 & 2560 & 1280 \\
231 & 1.280 & 1280 \\
229 & 160 & 160 \\
\hline
\end{tabular}

IDU: Immunodernatology Unit Johns Hopkins University UnB: Universidade de Brasilia.

Na UnB, empregávamos nesta fase lingua de rato soros dilu dos em PBS e conjugado da Biolab diluido a 1.20 .

$\mathrm{Na}$ IDU, empregamos pele humana, soros diluidos em TAS Cálcio e conjugado da Cappel geralmente diluddo a $1: 32$

TABELA 8

Comparaca entre titules obtidos na IDU e na UnB, na lase tincal

\begin{tabular}{lrrr}
\hline & \multicolumn{2}{c}{ TITULOS } & IDU \\
Soro N: & Ph & Ec & Ph \\
\hline 254 & 40 & 0 & 40 \\
250 & 640 & 80 & 320 \\
248 & 1.280 & 640 & 1.280 \\
243 & 80 & 40 & 80 \\
240 & 640 & 320 & 320 \\
221 & 320 & 160 & 320 \\
218 & 640 & 160 & 640 \\
217 & 160 & 80 & 40 \\
213 & 160 & 40 & 320 \\
212 & 160 & 80 & 320 \\
\hline
\end{tabular}

IDU: Immunodermatology Unit, Johns Hopkins University. UnB: Universidade de Brasilia

Ph: pele humana

Ec: esófago de cobaia

sos de PFF como de pénfigo vulgar ${ }^{1.25}$. As cres centes restriçóes ao uso de primatas em pesquisa estão limitando a utilizaçāo do esôfago de maca co nos Estados Unidos e no Brasil o alto preço e as dificuldades para a obtençào do esófago de macaco inviabilizam o seu emprego rotineiro. Este conjun to de motivos justifica a não inclusāo deste substrato na presente investigacan outh

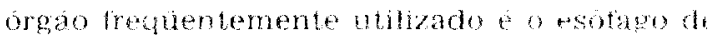
cobala ${ }^{21}$ is Recentemente elevado a condicas

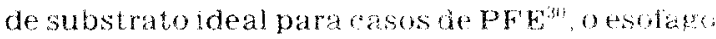
de cobaia forneceu em mosos expermentos rea coes menos intensas t thuos mats baixos do que a pelo homana la inpua he rato de tact obtencao loi o substrato que methor nos impres sionou na lase de estudos preliminares Fimpre

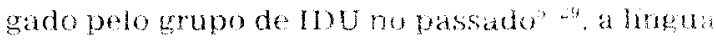
de rato mostrou em nosso estudo resultados on satisfatoria superposica aos obticios com pele humana (Tabela 7). Porem, com o emprego da língua de rato, tanto em nossa rasuistica cume, na do grupo da nou fordm observados soros de pessoas nomals com reacers pustuvas In cialmente, estes resulados form considerados como corroborando os achados de CASTRO et al." de que soros positivos podem ser encontra dos no seio da populaca aparentemente sadia de áreasendêmicas de PFF Contudo, o empregu da pele humana nos moldes preconiados pelo grupo da IDU tem fornecido constantemente reacoes negativas em pessods nomats ${ }^{l}$ Un th co caso de nossa soroteca que to positivonestas circunstancias apresenta lorte suspeita de troca e nova reaca recenterrente realizada com soro desta pessoa foi negativa E possivel ainda que reacós aparentemente falso positivas encon tradas em pessoas normals provenientes de áreas endemicas decorram da presença de anti corpos que reajam contra uma citoqueratina murina recentemente descrita e denominada an tígenos Cascas ${ }^{16}$. Tres de nossos soros positivos na reaçäo de imunofluorescencia indireta com lingua de rato e negativos com pele humana (so) ros $172,174,176$, pertencentes a pessoas sadias parentes de doentes com PFE. foram positivos aos antigenos Cascas em testes realizados na IDU. Este conjunto de dados é pois favoravel ao emprego da pele humana que tem oferecido resultados excelentes quando utilizada em asso ciaça aos demais procedimentos discutidos adiante. $O$ prepúcio de recem nascido a pele da cabeca e do pescoco: e, conforme verificamos no presente estudo, a pele da parede abdominal anterior prestam-se bem à execução da reaçăo. COMO SISON-FONACIER \& BYSTRYN ${ }^{32}$ de monstraram variaçoes topograficas na distribui çào de antígenos de pênfigo no corpo humano. e recomendado cuidado na escolha do local de origem da pele a ser utilizada como substrato. 
FRIEOMAN, H.: CAMPBELl. I. T.: ALVAREZ, R. R.: DIAZ, L. A.; CASTRO, R. M. de; ROITMAN, I.: PARREIRAS. R. M. \& RAICK. A. N. - Imunofluorescência indireta no pénfigo foliaceo endêmico. Contribuiçāo para sua padroniza (cal. Rev. Inst. Med. trop. S. Paulo, 31(3): 158 168, 1989

Com relaçào às variáveis potencialmente in fluentes sobre a reaçào, verificamos que o com posto OCT nāo a prejudicou e que seu emprego permitiu melhor orientação do substrato na constituiçảo do bloco, facilitando desta forma a realizaçáo dos cortes em criostato.

Já a utilizaçào da acetona teve efeito dele tério que in terpretamos agora como parcialmente decorrente das lavagens subseqüentes em PBS precedendo a incubação com os soros. De acordo com OGAWA et al: ${ }^{: 6}$, estas lavagens di. minuem a reatividade dos antigenos de pènfigo, fato confirmado por MATIS et al..$^{25}$ e por nossos experimentos (Tabelas 5 e 6 ).

A questāo de preservaçào antigènica foi ain. da considerada nos testes de congelamento rápido e lento e de armazenamento das lâminas. É curioso que os antigenos aparentemente se con servam bem tanto diante do congelamento lento como em face do armazenamento. O sucesso com o emprego de pele obtida em necrópsias ${ }^{2 / 3}$ demonstra, aliás, a resistência do sistema anti génico do pênfigo frente à autólise. Do ponto de vista prático, estas características sảo úteis por dispensarem o uso do nitrogénio liquido e por permitirem o armazenamento de substratos uu dos cortes já em lâminas, pelo menos por de terminado periodo de tempo (uma semana em nossos experimentos). F evidente contudo, que condiçoes ótimas, como a do emprego do nitro génio liquido e dos cortes ainda frescos, prepa rados no mesmo dia ou nos dias imediatamente anteriores, proporcionam menos riscos de insu cesso devendo ser sempre preferidas.

O emprego adequado do conjugado repre senta indubitavalmente ponto básico na realiza çāo das reaçôes de imunofluorescência ${ }^{13}$. O método de imunodifusāo radial ${ }^{*}$ para a titulaçāo do conjugado é económico, seguro, de reprodu çào fácil e de execuçāo rápida.

As reaçóes realizadas na IDU apresentaram excelente qualidade e contraste imunológico suficientemente claro para evitar dúvidas à leitura (Figura 2).

Nossos testes na etapa final, na UnB, empre. gando o esquema IV, demons traram a reprodutibilidade da reaçāo e asseguraram-nos o seu do mínio. Verificamos ainda que a pele humana é superior ao esoffago de cobaia.

Com relaçāo aos títulos obtidos, é importan te ressaltar que nenhum paciente em atividade clínica apresentou reaçāo negativa. Esta carac terizou pessoas sadias e doentes em inatividade. Há suspeita de troca de soro para a pessoa sadia que exibiu reação positiva.

A correlaçāo, nos 92 casos testados na IDU, entre a atividade clínica e o título de anticorpos séricos (Figuras 3 a 7 ) sugere à primeira vista associaçāo de tipo grupal mas nảo individual, isto é, a média dos títulos foi maior para a forma generalizada (média $=460,8$ ) do que para a forma localizada (média $=299,2$, mas alguns casos de forma localizada tiveram títulos mais elevados do que casos de forma generalizada. Isto confirmaria resultados de outros autores ${ }^{28.33}$ e reforçaria o conceito de alguns de que o emprego do título de anticorpos como parâmetro de atividade clínica e como orientador terapêutico não se justifica ${ }^{21}$. Contudo, observação mais minuciosa dos prontuários dos pacientes revelou que os grupos forma localizada e forma generalizada nāo sāo na realidade clinicamente homogêneos, havendo considerável variaçāo de grau de atividade clinica intra-grupal. Ainda, alguns pacientes sāo mantidos na forma localizada à custa de tratamento prolongado com doses de manutençào relativamente elevadas de imunodepres sores $(20 \mathrm{mg}$ ou mais de prednisona por dia). Estes pacientes com forma localizada mas com evoluçāo clínica marcada por recidivas e resistência à terapêutica habitual seriam talvez melhor classificados como "high responders" no conceito de DIAZ et al. ${ }^{17}$ no sentido de que res pondem intensamente ao agente desencadeante do PFE, com títulos elevados de anticorpos.

Analisando individualmente título e com portamento clínico, observamos que o título 160 parece representar marco de mau prognóstico por ser o limite inferior dos títulos encontrados na forma generalizada e por compreender pa cientes com forma localizada de difícil controle. Títulos acima de 160 pertenceram a pacientes com forma generalizada ou com forma localizada resistente à terapêutica. Acreditamos porém que tal observação só será confirn ada ou infïr mada através de futuras investigações clínico 
FRIEDMAN, H.; CAMPBELL, I. T; ALVAREZ, R, R.; DIAZ, L. A.: CASTRO, R. M. de: ROITMAN, I.: PARREIRAS. R. M. \& RAICK, A. N. - Imunofluorescência indireta no penfigo foliáceo endémico. Contribuiçāo para sua padroniza çào. Rev. Inst. Med. trop. S. Paulo, 31(3): 158-168, 1989.

sorológicas que, contando já com reaçāo devida mente padronizada, possam esmiuçar as formas clínicas atualmente reconhecidas de PFE, talvez subdividindo-as em grupos e enfocando as de mo do quantitativo, através de fórmulas que considerem o número de lesōes ou a área corpórea comprometida, o tipo e a atividade da lesão e as doses empregadas.

\section{SUMMARY}

\section{Indirect immunofluorescent reaction in endemicus pemphigus foliaceus.}

The aim of the present research was to standardize the indirect immunofluorescence reaction for Endemic Pemphigus Foliaceus (Fogo Selvagem). We found that fresh human skin was the ideal substrate and could proceed from fores kin, head, neck, or anterior abdominal wall. PBS pre-washing of the skin preceding the incubation with the serum should be avoided since the antigenicity might be diminished. TAS-calcium preserves the Pemphigus antigenic properties of the skin and shall be preferred as the diluent for the sera. Albumin-coated slides are useful becau se they increase the adherence of the skin sec tions. The conjugate appropria te dilution is con venientely determined by the radial immuno diffusion test (Ouchterlony method). So far as the correlation between the antibody titer and the clinical activity is concerned, we concluded that a titer of 160 or more was of bad prognosis, since it was associated with the generalized form of the disease or with cases of the localized form refractory to the usual therapy. Nevertheless, this assumption needs confirmation by further studies involving an appropriate clinical ap proach.

\section{AGRADECIMEN'TOS}

Agradecemos o auxílio técnico de Paula Bo nitz, Gerardine M. M. Finn, Pedro B. Araújo e Bráulio S. Santos Filho e a assistência fotográfica de Paulo H. B. Leite. Esta pesquisa foi em parte amparada financeiramente pelo Conselho Nacional de Desenvolvimento Científico e Tecnológico - CNPq (projeto $40.6319 / 84$ ) e pelo Decanato de Pesquisa e Pós-Graduaçāo da Fundaçāo Universidade de Brasília (projeto 54025)
REFERENCIAS BIBLIOGRAFICAS

1. ACOSTA, E. \& IVANYL. L. - Comparison of the reactivity of various epithelial substrates for the titration of Pem phigus antibodies by indirect immunofluorescence. Brit J. Derm., 107: 537541,1982

2. AHMED. A. R. - Clinical features of Pemphigus. Clin Derm.. 1: 1321,1983

3. AHMED, A. R; GRAHAM, J.; JORDON, R. E. \& PRO VOST. T. T. - Pemphigus current concepts. Ann. intern. Med., 92: 396.405, 1980.

4. ANHALT, G. J.; DIAZ. L. A.; LABIB, R. S. \& PROVOST T. T. .... Procedures Manual. Baltimore, Dermatology Unit Johns Hopkins Medical Institutions, 1987

5. ANHALT, G. J.: LABIB, R. S.: VOORHEES, J. J.: BEALS, 'T F \& DIAZ, L A - Induction of Pemphigus in neonata mice by passive transfer of IgG from patients with the disease New Engl. J. Med., 306: 1189.1196. 1982

6. AUAD. A. - Penfigo foliáceo sul americano no estado de Goiás Rev. Pat. trop., 1: 293346,1972

7. AVALOS, E.; PATEL, H. P.: ANHALT, G. J. \& DIAZ. L A - Autoimmune injury of squamous epithelium by Pem phigus autoantibodies. Brit. J. Derm., 111:359-365, 1984

8. BEUTNER, E. H.: JABLONSKA, S.: CHORZELSKI, T P. \& NISENGARD, R.J. - Reliability of indirect immuno fluorescence testing. Areh. Derm, 116: 1228 1229. 1980.

9. BEUTNER, E. H.; JORDON, R. E. \& CHORZELSKI, T P. - The immunopathology of Pemphigus and Bullous Pemphigoid. J. invest. Derm., 51: 63 80, 1968.

10. BEUTNER, E. H.: LEVER, W. F.: WITBESKY, E.; JOR DON, R. E. \& CHERTOCK, B. - Autoantibodies in Pem phigus Vulgaris: response to an intereellular substance of epidermis. J. Amer. med. Ass., 192: 682, 1965

11. CASTRO. R. M.; CHORZELSKI, T.; JABLONSKA, S. \& MARQUAR' JR.. A. - Antiepithelial antibodies in heal thy people living in an endemic area of South American Pemphigus Foliaceus (Fogo Selvagem. Preliminary re port. Castellania, 4: $111112,1976$.

12. CASTRO, R. M.: ROSCOE, J, T. \& SAMPAIO, S. A. P - Brazilian Pemphigus Foliaceus. Clin. Derm., 1: 2241 1983

13. CHORZELSKI, T. P. \& BEUTNER, E. H. - Factors con tributing to occasional failures in demonstration of Pem phigus antibodies by the immunofluorescence test. $J$. invest. Derm., 53: 188-191, 1969

14. CRESWELL, S. N.: BLACK. M. M.; BHOGAL, B. \& SKEE TE, M. V. H - Correlation of circulating intercellular anti body titres in Pemphigus with disease activity. Clin. exp. Derm., 6: 477 483, 1981

15. CUNHA. P. R. - Estudo soro-epidemiologico em foco de pênfigo foliaceo endêmico (Fogo selvagem) no Estado de Sáo Paulo. Sào Paulo, 1988. ITese de Doutoramento - Faculdade de Medicina da Universidade de Sāo Paulo 
FRIEDMAN, H.; CAMPBELL, I. T.; ALVAREZ, R. R.; DIAZ, L. A.; CASTRO, R. M. de; ROITMAN, I.; PARREIRAS, R. M. \& RAICK, A. N. - Imunofluorescencia indireta no pênfïgo foliáceo endèmico. Contribuiçāo para sua padroniza (à) Rev. Inst. Med. trop. S. Paulo, 31 (3): 158168.1989

16. DIAZ, L. A. SAMPAIO, S. A. F : RIVITTI, E A; MAR 'TINS, \&. R. UUNHA, P. R.: LOMBARDI, C; ALMEIDA. F. A: CASTRO. R. M: MACCA, M. L.: LAVRADO, C.: BORGES. P.: MINELLI. L.: EMPINOTTI, J. C.; FRIED MAN, H. CAMPBELL, I. T.; LABIB, R. S. \& ANHALT. G. $r$.... I. Endemie Pemphigus Foliaceus (Fogo selvagem). J. Amer. Acad Derm., 1988. (in press

17. DIAZ. L. A.: SAMPAIO, S. A. P.; RIVITTI, E. A; MAR TINS, C. R.: CUNHA, P. R.; LOMBARDI, C.: ALMEIDA, F. A.: CASTRO. R. M.: MACCA. M. L.; LAVRADO. C.: BORGES. P.: MINELLI, L.; EMPINOTTI, J. C.: FRIED MAN. I.: CAMPBELL, I, T.; LABIB, R. S. \& ANHALT G. J. Endemic Pemphigus Foliaceus (Fogo Selvagem: II. Current and historic epidemiologic studies $\mathbf{J}$. invest. Derm.. 1988 (in press).

18. FEIBELMAN, C, STOLZNER, G, \& PROVOST, T. T Sunerior sensitivity of monkey esophagus in the determi nation of Prophigus antibody Areh. Derm., 117:561563. $198:$

19 FITZPATFICK R. E \& NEWCOMER, V. D -- The corre lation of disease activity and antibndy titers in Pemphi gus Arch. Derm., 116: 285290,1980

20. GOLAN, D: GUILHAR, A: SHMUEL, Z \& MOSHKO WITZ, M. -- Autoantibodies to epithelial cells interce liular substancel and their correlation with clinical acti vity of Pemphigus Vulgaris. Dermatologica (Basel), 169: 339341.1984

31. JUDD, K. P. \& LEVER, W. F. -- Correlation of antibodies in skin and serum with disease severity in Pomphigus. Arch. Derm., 115: 428-432, 1979.

32. JUDD, K, P. \& MESCON, H. -- Comparison of different epithelial substrates useful for indirect immunofluores. cence testing of sera from patients with active Pemphigus. J. invest. Derm., 72: 314316,1979

3. KATZ, S. I.; HALPRIN, K. M. \& INDERBITZIN, 'T. M -..- The use of human skin for the detection of antiepithelial auto-antibodies. A diagnostic and prognostic test. J. invest. Derm., 53: 390 399, 1969

4. LEVER, W. F \& SCHAUMBURG LEVER. G. - Histopathology of the skin. 6th. ed. Philadelphia, J. B. Lippincott., 1983

25. MATIS, W. L.: ANHALT, G. J.; DIAZ, L. A.; RIVITTI E. A.; MARTINS, C. R. \& BERGER, R. S -- Calcium enhances the sensitivity of immunofluorescence for Pem phigus antibodies. J. invest. Derm., 88: $302304,1987$.

26. OGAWA, H.; TANEDA, A. \& MORIOKA, S. -- Characteri zation of Pemphigus antigen. J. invest. Derm., 70: 194196 , 1978.

27. PROENÇA, N \& CASTRO, R. M. - Pênfigo foliáceo sul a mericano. Rev. Hosp. Clín. Fac. Med. S. Paulo, 26: 115122 , 1971.

28. RIVITTI, E. A. - Eletroforese, imunoeletroforese, antiestreptolisina $O$ e anticorpos anti-epitélio no pênfigo foliáceo sul-americano. Estudo evolutivo. Sáo Paulo, 1972 'Te se de doutoramento -. Faculdade de Medicina da Univer sidade de Sào Paulo).

29. ROSCOE, J, T.: NAYLOR, P. H.; DIAZ, L. A ; LABIB, R. S.: PATEL, H. P.; GOLDSTEIN, A. L.: SAMPAIO, S. A. P. \& ANHALT. G. J - Elevated thymosin alpha 1 levels in Brazilian Pemphigus Foliaceus Brit. J. Derm., 115: $147-150,1986$.

30. SABOLINSKI, M. L.; BEUTNER, E. H.; KRASNY, S.; KU MAR, V.; HUANG, J.; CHORZELSKI, T. P.; SAMPAIO, S. A. P \& BYSTRYN. J.C. - Substrate specificity of antie pithelial antibodies of Pemphigus Vulgaris and Pemphigus Foliaceus sera in immunofluorescence tests on monkey and guinea pig esophagus sections. J. invest. Derm., 88: $545-543.1987$

31. SEVADJIAN, C. - Nosology of Brazilian Pemphigus Foliaceus. Int. J. Derm., 18:781.786, 1979

32. SISON-FONACIER, L. \& BYSTRYN, J, C, - Regional variations in antigenic properties of skin. J. exp. Med. 164: $2125-2130,1986$

33. TAKAHASHI, M. D. F. - Imunopatologia do pênfigo foliáceo sul-americano. Estudo por imunofluorescência direta e indireta. Sảo Paulo, 1981. (Dissertaçào de mestrado - Faculdade de Medicina da Universidade de São Paulo).

34. WEISSMAN, V : FEUERMAN, E. J.; JOSHUA, H. \& HA ZA. B - The correlation between the antibody titers in sera of patients with Pemphigus Vulgaris and their clinical state. J. invest. Derm., 71: $107109,1978$.

35. WENK. P. A. - Pre-coated slides can save time and headaches for histotechs. Detroit. Lab Tips from Lipshaw, 1986 .

Recebido para publicação em 16/9/1988 